\title{
Tenofovir Adherence in the Prevention of Mother-to-Child Transmission of Hepatitis B in the Democratic Republic of the Congo: A Qualitative Study Applying the Information-Motivation- Behavioral Skills Model
}

Sahal Thahir ( $\sim$ sahal.thahir@unchealth.unc.edu )

University of North Carolina at Chapel Hill

Camille E. Morgan

University of North Carolina at Chapel Hill

Patrick Ngimbi

Kinshasa School of Public Health

Kashamuka Mwandagalirwa

Kinshasa School of Public Health

Sarah Ntambua

Kinshasa School of Public Health

Jolie Matondo

Kinshasa School of Public Health

Martine Tabala

Kinshasa School of Public Health

Charles Mbendi

University of Kinshasa

\section{Didine Kaba}

Kinshasa School of Public Health

Marcel Yotebieng

Albert Einstein College of Medicine

Jonathan B. Parr

University of North Carolina at Chapel Hill

Kristin Banek

University of North Carolina at Chapel Hill

Peyton Thompson

University of North Carolina at Chapel Hill

\section{Research Article}

Keywords: adherence, tenofovir disoproxil fumarate, hepatitis B virus, Africa, PMTCT, DRC

Posted Date: January 10th, 2022

DOI: https://doi.org/10.21203/rs.3.rs-1146875/v1

License: (c) (1) This work is licensed under a Creative Commons Attribution 4.0 International License. Read Full License 


\section{Abstract}

Background: Hepatitis B virus (HBV) remains a leading infectious cause of death worldwide, and is highly prevalent in Sub-Saharan Africa (SSA). The prevention of mother-to-child transmission (PMTCT) programs for HBV are critical to reaching elimination targets and utilizing existing HIV testing and treatment infrastructure. Building on a feasibility study to introduce tenofovir disoproxil fumarate antiviral therapy to pregnant women with high-risk HBV in the Democratic Republic of the Congo (DRC), we examine the social and psychological facilitators of medication adherence of women who participated in this HBV PMTCT program.

Methods: This study utilizes a qualitative exploratory approach involving women in Kinshasa, DRC who were identified as high-risk HBV during pregnancy and completed the pilot tenofovir antiviral program. Six participants were identified and completed in-depth, open-ended phone interviews. This study adopts a modified Information-Motivation-Behavioral Skills model (IMB+) to identify emerging themes related to tenofovir adherence.

Results: A strong trust in healthcare workers, family support, and improved awareness of the disease and treatment options through enrollment in the PMTCT program facilitated tenofovir adherence. Barriers to medication adherence included social stigma and low healthcare literacy specific to HBV.

Conclusions: Our study highlights the feasibility of medication adherence in HBV PMTCT programs in a low-resource setting and the importance of incorporating initiatives that address hepatitis B stigma and other social barriers. These findings are relevant to future HBV PMTCT scale-up, which is needed in the DRC and in similar African contexts with high HBV prevalence.

Trial registration: The parent study was registered with clinicaltrials.gov under identifier NCT03567382. Date of registration: $25 / 06 / 2018$

\section{Introduction}

Despite an effective vaccine, hepatitis B virus (HBV) remains a leading infectious cause of death worldwide, especially in subSaharan Africa (SSA). ${ }^{1}$ Prevention of mother-to-child transmission (PMTCT) is a key part of the World Health Organization (WHO)'s global HBV elimination strategy due to infants' high exposure risk and vulnerability for developing chronic infection. ${ }^{2}$ Current WHO guidelines for PMTCT of HBV focus on timely birth-dose HBV vaccination of all infants and peripartum antiviral prophylaxis with tenofovir disoproxil fumarate (TDF) for pregnant women at high-risk of transmission. ${ }^{3}$

In the Democratic Republic of the Congo's (DRC) capital city of Kinshasa, where HBV remains prevalent at $4.9 \%,{ }^{4}$ our group has demonstrated the feasibility and acceptability of using existing HIV PMTCT infrastructure for HBV PMTCT implementation. Through the Arresting Vertical Transmission of HBV (AVERT-HBV) study, we conducted antenatal HBV screening to identify women with HBV, treat women with high-risk HBV, and provide timely HBV birth-dose vaccination to all infants born to women with HBV. ${ }^{5}$ While antenatal HBV screening and treatment is similar to and can thus leverage HIV PMTCT programs, HBV is a less well-known infection ${ }^{6,7}$ and HBV PMTCT less widely implemented compared to HIV. ${ }^{8,9}$ As such, very little is known about adherence to antiviral prophylaxis and its facilitators within HBV PMTCT programs. The AVERT-HBV parent study initially assessed TDF adherence by quantifying TDF's active moiety, tenofovir diphosphate (TFVdp), in dried blood spots collected at delivery. Only one woman was found to have TFVdp levels reflective of full adherence. These findings prompted follow-up qualitative interviews with mothers in the study who received TDF prophylaxis to learn about their experience with the medication.

To our knowledge, no studies have evaluated social and psychological determinants in the context of prophylaxis for HBV PMTCT. Few studies have analyzed the social and psychological facilitators of adherence to HBV antiviral therapy within chronic treatment programs, not specific to pregnant women. Urban residence, non-cirrhotic status, and family member reminders predicted high adherence ${ }^{10}$ and adherence was higher with tenofovir alafenamide than entecavir. ${ }^{11}$ None of these studies applied a behavioral model to identify barriers and facilitators of adherence to antivirals systematically.

This qualitative study used the information-motivation-behavior (IMB) model to explore the knowledge, motivation, health behaviors, and modulating factors that affect adherence to TDF prophylaxis among HBV-infected pregnant women. The IMB model has been shown to be an effective theoretical foundation for assessing HIV-related adherence behaviors in both high- and low-resource settings, ${ }^{12-14}$ and ideal for adapting to a HBV PMTCT program that utilized existing HIV infrastructure.. ${ }^{5}$ The systematic 
characterization of these factors described by women with high-risk HBV can inform scale-up of HBV PMTCT programs, which is necessary to reduce HBV-specific morbidity and mortality.

\section{Materials And Methods \\ Setting}

This study was conducted within the Arresting Vertical Transmission of HBV (AVERT-HBV) study in Binza and Kingasani maternity centers, ${ }^{5}$ two of the highest-volume maternity centers in Kinshasa, DRC, the second-largest city in Africa with an estimated population of 15 million people. ${ }^{15}$ The parent study utilized existing infrastructure for HIV screening and PMTCT by incorporating HBV screening, peripartum tenofovir disoproxil fumarate (TDF) therapy of women at high risk of HBV transmission based on viral load $\left(>200,000 \mathrm{IU} / \mathrm{mL}\right.$ ) or HBV e antigen (HBeAg) positivity, and monovalent HBV birth-dose vaccination for all infants. ${ }^{5}$

\section{Participants}

Pregnant women who sought care at either maternity center between September 2018 and February 2019 were provided group counseling on HBV and subsequently invited to be screened for HBV using HBV surface antigen (HBsAg) rapid diagnostic tests. Pregnant women who were HBsAg-positive, older than 18 years of age, $\leq 24$ weeks' gestation, healthy without requiring hospitalization during pregnancy, and intending to continue maternity and post-partum care at these respective maternity centers, were enrolled in the AVERT-HBV study $(n=90)$. HBV viral load and HBeAg testing were completed in-country upon enrollment, and HBV viral load was subsequently repeated at delivery and 6-months after delivery. Women with high-risk HBV (viral load $>200,000$ $\mathrm{IU} / \mathrm{mL}$ or HBeAg-positive at enrollment) were provided TDF prophylaxis starting between 28 and 32 weeks of gestation and continuing through 12 weeks' post-partum, following WHO HBV PMTCT guidelines. The AVERT-HBV parent study identified ten women who were high-risk for transmission, nine of whom agreed to TDF prophylaxis, and one of whom withdrew from the study prior to 28 weeks of gestation. A total of nine women received the once-daily TDF regimen prior to delivery through 12 weeks postpartum. Those who agreed to phone interviews were enrolled and participated in the present study approximately six to nine months after completing the AVERT-HBV parent study.

\section{Information-Motivation-Behavior Model}

Fisher et al. first proposed the IMB model, outlining three constructs: (1) Information includes pertinent medication knowledge including administration, side effects, and broader understanding of adherence-related outcomes; (2) Motivation includes personal and social influences on medical adherence; (3) Behavioral skills includes the individual's objective and perceived capacity to complete adherence-related tasks. ${ }^{16}$ An updated version of the IMB model also describes how personal or contextual factors may influence the different IMB constructs. ${ }^{12}$ This study used the newer modified model as the analytical framework for this study.

\section{Data Collection and Analysis}

Study staff from the Kinshasa School of Public Health conducted phone interviews with women who received TDF prophylaxis. Written informed consent was received from women in the parent study, and verbal consent was received for telephone interviews and recordings. Interviews were conducted in French or Lingala based on the woman's preference. After verbal consent was provided, the women were asked broadly about their experiences with study enrollment, perceived benefits and side effects of tenofovir, factors affecting their medication adherence, and social impacts of their new HBV diagnosis and prophylaxis. The complete interview guide can be found in the supplementary materials (S-1). The research team recorded, transcribed, and translated interviews from Lingala to French and then to English. Using the modified IMB model, three team members separately coded the data by hand and aggregated responses based on respective themes.

\section{Results}

\section{Participant characteristics}

Six women agreed to be interviewed for this study; all were newly diagnosed with HBV during the original study, and none tested positive for HIV. The ages of participating women ranged from 19 to 35 years with a median age of 25 (Table 1). Four of these women were seen at the Binza Maternity Center, and two were seen at the Kingasani Maternity Center. The current pregnancy was 
first for one woman, the second for four women, and the eighth for one woman. Almost all women (five of six) were married or in a marriage-like relationship. Three of six women had achieved post-secondary education. Two of the six women reported a source of employment at the time of TDF therapy.

Table 1

Individual and household characteristics of the interview participants

\begin{tabular}{|c|c|c|c|c|c|c|c|c|c|}
\hline ID & $\begin{array}{l}\text { Maternity } \\
\text { center }\end{array}$ & $\begin{array}{l}\text { Age } \\
\text { (years) }\end{array}$ & $\begin{array}{l}\text { Total } \\
\text { pregnancies }\end{array}$ & $\begin{array}{l}\text { Gestational } \\
\text { age at } \\
\text { AVERT } \\
\text { enrollment }\end{array}$ & $\begin{array}{l}\text { Household } \\
\text { size* }^{\star}\end{array}$ & $\begin{array}{l}\text { Marital } \\
\text { status }\end{array}$ & Education & $\begin{array}{l}\text { Wealth } \\
\text { quartilet, } \\
\neq\end{array}$ & Employment \\
\hline 1 & Binza & 35 & 8 & 24 & 6 & Married & Secondary & $\begin{array}{l}\text { Upper-to- } \\
\text { middle }\end{array}$ & $\begin{array}{l}\text { Self- } \\
\text { employed }\end{array}$ \\
\hline 2 & Kingasani & 25 & 2 & 12 & 2 & Married & $\begin{array}{l}\text { Higher } \\
\text { education }\end{array}$ & Highest & $\begin{array}{l}\text { Not } \\
\text { currently } \\
\text { working }\end{array}$ \\
\hline 3 & Binza & 26 & 2 & 22 & 9 & - & $\begin{array}{l}\text { Higher } \\
\text { education }\end{array}$ & $\begin{array}{l}\text { Lower-to- } \\
\text { middle }\end{array}$ & $\begin{array}{l}\text { Not } \\
\text { currently } \\
\text { working }\end{array}$ \\
\hline 4 & Kingasani & 25 & 1 & 24 & 1 & Married & Primary & Highest & $\begin{array}{l}\text { Someone } \\
\text { else }\end{array}$ \\
\hline 5 & Binza & 19 & 2 & 20 & 5 & $\begin{array}{l}\text { Marriage- } \\
\text { like } \\
\text { relationship }\end{array}$ & Secondary & Highest & $\begin{array}{l}\text { Not } \\
\text { currently } \\
\text { working }\end{array}$ \\
\hline 6 & Binza & 23 & 2 & 22 & 2 & Married & $\begin{array}{l}\text { Higher } \\
\text { education }\end{array}$ & $\begin{array}{l}\text { Lower-to- } \\
\text { middle }\end{array}$ & $\begin{array}{l}\text { Not } \\
\text { currently } \\
\text { working }\end{array}$ \\
\hline \multicolumn{10}{|c|}{$\begin{array}{l}\text { *Household size taken from enrollment at the parent study and does not include the child with whom the women were pregnant } \\
\text { in the parent study. }\end{array}$} \\
\hline \multicolumn{10}{|c|}{ TQuartiles taken from distribution of the entire parent study population. } \\
\hline
\end{tabular}

The six women interviewed were either virally suppressed at delivery or had decreased viral loads at delivery compared to enrollment (Table 2). Four (IDs 1-4) of the six women interviewed had detectable TFVdp in blood samples collected at delivery (Table 2), two of whom (IDs 3 and 4) initiated TDF within 28 days of delivery. The two women with detectable TFVdp who initiated TDF >28 days before delivery (IDs 1 and 2) reported the most consistent adherence; they were also observed to have the largest increase in creatinine, a marker of kidney function, and known side effects of TDF therapy (Table 2). ${ }^{17}$ Two women with detectable TFVdp who initiated TDF within 28 days of delivery (IDs 3 and 4) reported poor adherence in the first week of therapy, but consistent adherence thereafter. The two women with undetectable TFVdp (IDs 5 and 6) reported intermittent adherence at the beginning of therapy. 
Table 2

Qualitative and quantitative measures of tenofovir adherence

\begin{tabular}{|c|c|c|c|c|c|c|c|}
\hline ID & $\begin{array}{l}\text { TDF } \\
\text { initiation } \\
\text { (days from } \\
\text { delivery) }\end{array}$ & $\begin{array}{l}\text { Number of } \\
\text { completed weeks } \\
\text { on therapy prior to } \\
\text { delivery }\end{array}$ & $\begin{array}{l}\text { Pill bottle } \\
\text { check at } \\
\text { monthly } \\
\text { visits }\end{array}$ & $\begin{array}{l}\text { Self-reported } \\
\text { adherence* }\end{array}$ & $\begin{array}{l}\text { TFVdp at } \\
\text { delivery }\end{array}$ & Viral load trend $^{\dagger}$ & $\begin{array}{l}\text { Creatinine } \\
\text { change }\end{array}$ \\
\hline 1 & $\geq 28$ & 7 & $\begin{array}{l}\text { Empty at } \\
\text { all visits }\end{array}$ & Yes & Detectable & $\begin{array}{l}\text { Increased at delivery } \\
\text { but still virally } \\
\text { suppressed }\end{array}$ & $\begin{array}{l}0.38 \text { to } \\
0.57 \\
(+50.0 \%)\end{array}$ \\
\hline 2 & $\geq 28$ & 9 & $\begin{array}{l}\text { Empty at } \\
\text { all visits }\end{array}$ & Yes & Detectable & $\begin{array}{l}\text { Reached viral } \\
\text { suppression at } \\
\text { delivery and } \\
\text { sustained at 6- } \\
\text { months }\end{array}$ & $\begin{array}{l}0.60 \text { to } \\
0.96 \\
(+60.0 \%)\end{array}$ \\
\hline 3 & $<28$ & 1 & $\begin{array}{l}\text { Empty at } \\
\text { all visits }\end{array}$ & $\begin{array}{l}\text { Yes except } \\
\text { week } 1\end{array}$ & Detectable & $\begin{array}{l}\text { Decreased at delivery } \\
\text { but not virally } \\
\text { suppressed }\end{array}$ & $\begin{array}{l}0.72 \text { to } \\
0.59 \\
(-18.1 \%)\end{array}$ \\
\hline 4 & $<28$ & 2 & $\begin{array}{l}\text { Empty at } \\
\text { all visits }\end{array}$ & $\begin{array}{l}\text { Yes except } \\
\text { week } 1\end{array}$ & Detectable & $\begin{array}{l}\text { Decreased and virally } \\
\text { suppressed by } 6 \text { - } \\
\text { months }\end{array}$ & $\begin{array}{l}0.76 \text { to } \\
0.68 \\
(-10.5 \%)\end{array}$ \\
\hline 5 & $\geq 28$ & 6 & $\begin{array}{l}\text { Empty at } \\
\text { all visits }\end{array}$ & $\begin{array}{l}\text { Intermittent } \\
\text { initially, and } \\
\text { improved with } \\
\text { time }\end{array}$ & Undetectable & $\begin{array}{l}\text { Decreased at delivery, } \\
\text { rebound at } 6 \text {-months } \\
\text { but remained virally } \\
\text { suppressed }\end{array}$ & $\begin{array}{l}0.52 \text { to } \\
0.47 \\
(-9.6 \%)\end{array}$ \\
\hline 6 & $\geq 28$ & 5 & $\begin{array}{l}\text { Empty at } \\
\text { all visits }\end{array}$ & $\begin{array}{l}\text { Intermittent } \\
\text { initially, and } \\
\text { improved with } \\
\text { time }\end{array}$ & Undetectable & $\begin{array}{l}\text { Decreased at delivery, } \\
\text { rebound at } 6 \text {-months } \\
\text { but remained virally } \\
\text { suppressed }\end{array}$ & $\begin{array}{l}0.57 \text { to } \\
0.69 \\
(+21.1 \%)\end{array}$ \\
\hline
\end{tabular}

\section{The IMB+ model for tenofovir adherence}

Responses from the six participants who shared their experiences taking tenofovir were mapped to show how information, motivation, and behavior skills influenced TDF adherence. All participants discussed personal and contextual factors beyond the traditional IMB model that affected their adherence are grouped as modulating factors (Figure 1).

\section{Information}

The information component of the IMB model for TDF adherence was represented in the participants' understanding of the regimen, the purpose of treatment, perceived side effects, and the HBV disease process. A key component of this concept is the patient's comprehension of their diagnosis with HBV. Many of the participants highlighted that the first time they had heard of HBV was at study enrollment. One participant discussed the poor awareness of HBV she had prior to being tested, a theme shared by four of the six participants.

"... [maternity center staff] informed me that I have hepatitis and [they] explained well to me what hepatitis is, and then [they] gave me appointments, and we met with them at each appointment and four months after I started this treatment if I hadn't forgotten." (ID 1)

"I knew when [maternity center staff] say to take a drug during pregnancy, I guess it's already been proven that it won't have a negative effect on the child, so I had total confidence in the team that was treating me, so I had no fear on that side." (ID 6)

Participants also shared their knowledge of the benefits of TDF therapy and daily medication adherence in preventing MTCT of HBV. One participant shared her advice for other HBV+ pregnant women considering TDF therapy and discussed how she felt the regimen would cure her disease. 
"What I can say as advice to pregnant women, if you get hepatitis if you give them the medication, that they take it every day is for their own good, so that it treats them and cures them of this disease." (ID 2)

Adherence-related information was also represented in participants' discussion of perceived side effects of TDF. Half of the participants interviewed mentioned fatigue as a side effect after starting TDF therapy. One mother described this side effect in detail.

"I felt a little uncomfortable and when I took this medication. I felt tired, sleepy... I would need a little rest, I would have to sleep for a few minutes, and when I woke up, I could feel much better... all that was just the effects of the medication." (ID 2)

\section{Motivation}

The concept of motivation was represented by participants' discussion of the social influences and their personal incentives contributing to TDF adherence. One form of social motivation for adherence mentioned was an overall trust in healthcare workers. One participant illustrated this concept by discussing how other women living with HBV should share her trust in healthcare workers, in the benefits of TDF adherence for her health. The idea of having trust in health workers was a narrative shared by two other participants.

"[Future pregnant mothers] should trust you, the health care team, and that if you give them the medication, it is for their health and that they should take the medication well to have a complete recovery and they should avoid listening to everything we hear in the city." (ID 1)

Another participant also demonstrated the same sentiment of trust by discussing how her trust in the medical team helped spur her adherence to TDF during the study.

"I wasn't afraid [of taking tenofovir] because I know that when the doctor says something, it is for the well-being of the patient. That's why I wasn't afraid, and I was obliged to take the medicine, it was for my own healing." (ID 2)

An additional social motivation for adherence was the emotional support of family members, specifically when participants shared their new diagnosis. Many participants shared how family members encouraged them at the time of diagnosis. One participant shared how her initial interactions with her partner eased her anxiety about her new diagnosis and encouraged her TDF adherence.

"When I came home, I explained to my husband that I had caught hepatitis and I was panicking the day I spoke with you; As my husband is a laboratory technician, he started to comfort me, 'there is nothing to worry about, you are not going to die today, you are going to take the medication, and you are going to feel better." (ID 2)

Internal motivation for medication adherence was primarily defined by participants' perceived positive outcomes to themselves and their unborn children. All participants shared that their perceived personal benefits of TDF adherence as the primary motivation for adherence.

"[The medical staff] had explained to me the advantage of taking the medication and especially that I was still pregnant, I was protecting the health of my future child." (ID 1)

"I wasn't afraid [of taking tenofovir]; I trusted the doctor about the medication he had given me, and I knew it was going to be for the well-being of my health and my baby" (ID 2)

"It was because I had been caught with the microbe, and the doctor told me that I had to take this medicine for my healing. That's why I was motivated to take it so that I would be healed quickly. I don't like the disease, and I don't want it to get worse is what motivated me to take the medication." (ID 6)

\section{Behavioral Skills}

Women in this study described behavioral skills they used to assist them in taking TDF daily. Strategies included prayer, social support, and visual cues to remind them to take the daily dose. One participant described the routine she developed with her mother after she first came home with her diagnosis, which involved prayer to help ease her anxiety when taking the medication. 
"I didn't feel afraid [to take the medication] as [the maternity center staff] had explained to me how to take the medication. When it's time for me to take the medication, I take the water and the medication, I pray, and then I swallow the medication until I had reached the end. I didn't really feel afraid." (ID 2)

The same participant also described asking her sister to help her to maintain adherence during the study period.

"My little sister lives with me, and I showed her the medicine. I told her if I did not take [the medicine] to please remind me. (ID 2)

One woman reported that she had difficulty remembering to take the medication. To remind herself, she placed the bottle in a location where she would remember to take the medication every day.

"I put it [the bottle] next to my baby's stories so that I could see it every time I took it, so that I would always remember to take it." (ID 4)

\section{Modulating Factors}

In addition to information, motivation, and behavioral skills that influenced treatment adherence, we found several general modulating factors that influenced adherence. A main modifying factor that emerged from the data was the barrier of social stigma of HBV. A participant discussed the stigma she felt while taking the medication, causing her to hide the medication and her condition from her community.

"I just didn't want people to see my medication to avoid too many questions about it, knowing my environment, people always talk badly. That's why I didn't want other family members to see me with this medication." (ID 6)

The same woman described an incident during the study period where a visit by study staff was followed by rumors about her illness, causing her embarrassment and a missed follow-up appointment at the maternity center. Despite this social influence, she reported maintaining TDF adherence.

"Yes, in fact, there was a time when I didn't come to the center for follow-up, [the study nurse] had sent someone from the center to pick me up, and when the man arrived at my house, he met my cousin, and I stayed with her, and this cousin was able to turn the message into saying that I have HIV all over the [place], and it had weakened me a lot, and I was very worried when I took the medication, but then I didn't care about that, I remained objective when I took my medication until I was cured." (ID 6)

Another woman also shared her experiences with social stigma and embarrassment in relation to HBV and TDF adherence, which was quelled by interactions with healthcare workers.

"...the first day I was given the medication, I felt embarrassed with a fear that people would find out that I had the disease, but after some explanations from [maternity center staff] I had finally gotten rid of that embarrassment."(ID 2)

Medication characteristics and side effects were also mentioned as factors influencing treatment adherence. One participant mentioned that she had difficulty with the pill size as an initial barrier to adherence, though she became more comfortable with the medication over time. Another participant described fatigue in her experience with taking the medication:

"At the beginning of the treatment, I forgot to take it. I was taking it with difficulty because the tablets were large." (ID 4)

"I felt a little uncomfortable, and when I took this medication I felt tired, sleepy and especially as I was still big [pregnant] and I would need a little rest, I would have to sleep for a few minutes, and when I woke up I could feel much better until I had given birth I kept on taking it, so it was more fatigue, but for a while, I came back strong, all that was just the effects of the medication." (ID 2)

\section{Reasons for non-adherence}

While most women took the medication as prescribed, a few participants described missing doses. One woman reported a lack of having food as a reason for missing doses, as she perceived taking medication on an empty stomach would make her feel bad.

"Yes, I have missed days to take the medication. It's hunger, sometimes I missed something to eat, and as you know the medicine with hunger doesn't work. When you take the medication on an empty stomach, you will feel very bad." (ID 3)

Page $7 / 13$ 
Another participant reported that she simply forgot to take the medication initially; however, she could take it just like paracetamol when she became more familiar with the medication.

"Yes, a little bit of forgetting, but that didn't happen several times. I took my medication every day. At first, I tended to forget, but as time went by, when I became familiar with this medication, I took it like paracetamol. I don't remember how many times I missed taking the medication, but it wasn't much, I think it was only 3-4 days. [The reason I didn't take the medication every day] is forgetting, and also I didn't have the courage to take the medication at the beginning of the treatment." (ID 6)

A woman reported that the size of the pills led her to forget to take the medication. However, as she continued to receive refills at follow-up visits throughout the course of treatment, she adjusted to taking it, hoping it would address the disease.

"...at times I also forgot to take the medication for three days, but when I saw that she kept giving me the bottle of medication all month long, I said to myself, 'Good, as I am taking their medication, I think it's a reality and that maybe with this medication this disease will be able to end, that's when I became aware of it, and I began to respect the medication." (ID 4)

\section{Discussion}

This is one of the first studies to evaluate tenofovir disoproxil fumarate (TDF) adherence for the prevention of mother-to-child transmission (PMTCT) of hepatitis B (HBV) in a sub-Saharan African setting. We conducted qualitative interviews with six women with high-risk HBV to assess the information, motivation, behavioral skills, and modifying factors that facilitated or inhibited their adherence to TDF. These findings can inform HBV prevention and treatment programs in the region, which need to be expanded for improved HBV control. ${ }^{18}$

A key facilitator of adherence for individuals in this study was trust in clinical staff, along with the education those staff provided about TDF treatment. Having supportive patient-provider relationships and high trust in health workers has improved patient access to services, cooperation, and adherence to medications in other studies. ${ }^{19-21}$ Trust in health workers has also been shown to improve the acceptance and effectiveness of community-based maternal-child health initiatives, ${ }^{22}$ especially adherence to antiretrovirals in PMTCT programs. ${ }^{23}$ It is important to note the antenatal care context of this program, as participating women either previously had or actively built rapport with clinical staff during routine obstetric care. The established trust that women had with the clinical staff was beneficial for a program addressing a chronic disease like HBV, a disease where knowledge and awareness are low in endemic areas. ${ }^{24}$ Such familiarity with and trust in healthcare workers may be limited for chronic HBV treatment programs outside of an antenatal care setting. For an infection with which many are unfamiliar, a supportive care setting can play an essential role in facilitating medication adherence.

Interviews also highlighted the resiliency women had following their diagnosis of HBV during antenatal care. While there is limited literature on HBV treatment adherence, HIV literature has demonstrated that factors including optimism, self-efficacy, spirituality/religiousness, and social support, all of which were exhibited by participants in this study, are key to resiliency in ART adherence. ${ }^{25}$ Participants shared the vital role of social support in ensuring medication adherence. These interviews reflect the uncertainty and fear women had following their diagnosis, and the support they sought from their families (e.g., husband, sister, mother) or the healthcare staff at the maternity centers. Though the evidence is mixed, such social support has been observed to improve adherence in HIV treatment. ${ }^{26-29}$

In addition to facilitating factors, this study identified barriers to optimal TDF adherence, such as pill size, social stigma, and limited baseline knowledge about HBV and treatment thereof. Medication characteristics, such as pill size and quantity, are noted by the US Food and Drug Administration as barriers for medication adherence ${ }^{30,31}$; however, in this context, barriers related to medication characteristics eased over time once the participants became accustomed to the treatment. Participants identified fear of stigma, a known impeding factor to seeking care and adhering to treatment for $\mathrm{HBV}_{1}^{32}$ particularly following diagnosis, as a barrier to adherence. Most notably, they feared that people around them would misconceive HBV as HIV, a more widely known and stigmatized infection. ${ }^{33}$ As with pill size, the fear of stigma appeared to decrease over the course of the treatment. This finding is similar to findings from the literature on the effects of stigma on tuberculosis (TB) treatment adherence. Treatment for TB is similar to HBV prophylaxis for PMTCT in its finite course, and generally, social stigma does not appear to decrease adherence to TB treatment consistently. ${ }^{34,35}$ 
Overall, study participants had little knowledge of prevention, transmission, or symptoms of HBV. Low HBV knowledge has been documented across the region ${ }^{36-38}$ and particularly among pregnant women. ${ }^{39}$ Beliefs, whether based on truth or not, can improve adherence, ${ }^{40}$ but are generally found to be less effective than improved knowledge in the disease process and therapy. ${ }^{41,42} \mathrm{~A}$ critical misguided belief observed in this study was that the treatment would cure the women of HBV. While some women reported this as a motivating factor for medication adherence, the presence of this belief reflects a broader misunderstanding of HBV disease. Similar misunderstandings have been documented as a reason for poor adherence to ART in studies of HIV treatment adherence. ${ }^{43}$ The interviews also highlighted other misconceptions that worsened adherence, including the belief by one woman that food intake was required with medication. While food intake is not required for the medication, ${ }^{17}$ this misconception led to poorer adherence in this case. Food insecurity has been described as a factor decreasing ART adherence in people living with HIV, which is likely to apply in HBV treatment adherence as well. ${ }^{44}$

This study has a few notable limitations. First, the manual transcription and subsequent translation of these interviews may have led to some loss of descriptive meaning and context. Second, we conducted these interviews six to nine months after completing the parent study, which was 12 to 14 months after completion of their TDF treatment courses, including a three-month delay due to the COVID-19 pandemic. Such a lag in time may have led to recall bias. Participants' recollections of events may have changed over time, thus omitting factors that may have influenced TDF adherence and reducing the accuracy of this data. Additionally, the six women with high-risk HBV who were available and willing to participate might have noteworthy differences of experience with TDF adherence compared with the three other women with high-risk HBV who were not interviewed. Further, the women seeking antenatal care at the two study maternity centers in this study might not represent women seeking care at other maternity hospitals in Kinshasa. While both recall and selection bias may have influenced the findings from this study, the consistency of themes across participants suggest that the factors identified apply to women similar to those included in this analysis. As scarse research has been conducted on HBV treatment adherence, these findings are still informative for developing future research and treatment programs, especially within antenatal care settings in sub-Saharan Africa.

\section{Conclusions}

Our study highlights the value of qualitative data and laboratory markers to identify factors influencing adherence to TDF prescribed for the prevention of maternal-to-child HBV transmission. Pregnant women enrolled in an antiviral program in the DRC identified patient trust in health workers, improved disease awareness, and family support were key facilitators to TDF adherence. Fear of disease stigma and low health literacy were barriers to adherence upon initiating therapy. These findings are relevant to the development and expansion of hepatitis treatment programs in the DRC and other high prevalence countries.

\section{Abbreviations}

ART: anti-retroviral therapy

AVERT: Arresting Vertical Transmission of Hepatitis B Virus in the DRC (parent study)

DRC: the Democratic Republic of the Congo

HAART: highly active anti-retroviral therapy

HBV: Hepatitis B virus

HBeAg: Hepatitis B virus e antigen

HBsAg: Hepatitis B virus surface antigen

IMB: Information-Motivation-Behavioral Skills model

PMTCT: Prevention of mother-to-child transmission

TDF: tenofovir disoproxil fumarate 
TFVdp: tenofovir diphosphate

\section{Declarations}

\section{Ethics approval}

The study was conducted according to the guidelines of the Declaration of Helsinki, and approved by the Institutional Review Board at the University of North Carolina at Chapel Hill (IRB\# 17-2090) and the Kinshasa School of Public Health (CE/ESP/001/2018).

\section{Informed consent}

Written informed consent was obtained from all subjects for the parent study. Verbal informed consent was obtained prior to each telephone interview. There are no identifying images or information in this publication.

\section{Consent for publication}

The authors of this submission accept the conditions of submission and the BMV Copyright and License Agreement.

\section{Availability of data and materials}

The datasets generated and/or analyzed during the current study are not publicly available because they contain protected health information but are available from the corresponding author on reasonable request.

\section{Funding}

This study was funded by the Gillings Innovation Laboratory award. The Gillings Innovation Laboratory award was funded by the 2007 Gillings Gift to the University of North Carolina-Chapel Hill's Gillings School of Global Public Health. The HIV prevention of mother-to-child transmission study whose infrastructure was leveraged for this project was supported by NIH grants (NICHD R01HD087993 and NIAID U01AI096299). Tenofovir diphosphate testing was done by the University of North Carolina Center for AIDS Research Clinical Pharmacology and Analytical Chemistry Core, an NIH funded program (P30AI050410). PT received salary support from an NIH grant (NIAID K08AI148607) and from an ASTMH/Burroughs-Wellcome Fellowship in Tropical Medicine. CEM received support for this study from a fellowship from the University of North Carolina Graduate School. KB is supported by the UNC Training in Infectious Disease Epidemiology (TIDE) T32 training grant supported by the of the National Institutes of Health through the National Institute of Allergy and Infectious Diseases Award Number T32AI070114 and the NIH Research Training Grant D43009340, funded by the NIH Fogarty International Center NHBLI, NINDS, NCI, NINR, NIAID, and NIEHS. The content is solely the authors' responsibility and does not necessarily represent the official views of the National Institutes of Health.

\section{Authors' contributions}

PT, PN, KM, and JP designed the study. PN, JM, and SN collected the data. ST, CM, and KB analyzed the data. ST, CM, KB and PT wrote the first draft. All authors approved the final draft.

\section{Acknowledgements}

We thank all of the women who participated in this study, the staff at the Binza and Kingasani maternity clinics, and provincial and national health authorities. We would like to thank Dr. Noro Ravelomanana, and Dr. Bienvenue Kawende for their contributions to the parent AVERT study.

We are grateful for the support we have received from the administrative staff at the University of North Carolina and at Kinshasa School of Public Health. We grieve the loss of Prof Steven Meshnick, who had a major role in this study and whose vision and mentorship were critical to its success.

\section{Conflicts of Interest}

Outside of the submitted work, JP reports research support from Gilead Sciences, the World Health Organization; non-financial support from Abbott Diagnostics; and an honorarium from Virology Education. 


\section{References}

1. World Health Organization, World Health Organization, \& Global Hepatitis Programme. Global hepatitis report, 2017. (2017).

2. World Health Organization. Hepatitis B. https://www.who.int/news-room/fact-sheets/detail/hepatitis-b.

3. World Health Organization. Interim guidance for country validation of viral hepatitis elimination. (World Health Organization, 2021).

4. Thompson, P. et al. Seroepidemiology of Hepatitis B in the Democratic Republic of the Congo. Am. J. Trop. Med. Hyg. 101, 226229 (2019).

5. Thompson, P. et al. Arresting vertical transmission of hepatitis B virus (AVERT-HBV) in pregnant women and their neonates in the Democratic Republic of the Congo: a feasibility study. Lancet Glob. Health S2214109X21003041 (2021) doi:10.1016/S2214109X(21)00304-1.

6. Brouard, C. et al. Hepatitis B knowledge, perceptions and practices in the French general population: the room for improvement. BMC Public Health 13, 576 (2013).

7. Chaquisse, E., Meireles, P., Fraga, S., Mbofana, F. \& Barros, H. Knowledge about HIV, HBV and HCV modes of transmission among pregnant women in Nampula - Mozambique. AIDS Care 30, 1161-1167 (2018).

8. Woodring, J. Progress Toward Hepatitis B Control and Elimination of Mother-to-Child Transmission of Hepatitis B Virus Western Pacific Region, 2005-2017. MMWR Morb. Mortal. Wkly. Rep. 68, (2019).

9. Wilson, P., Parr, J. B., Jhaveri, R. \& Meshnick, S. R. Call to Action: Prevention of Mother-to-Child Transmission of Hepatitis B in Africa. J. Infect. Dis. 217, 1180-1183 (2018).

10. Xu, K. et al. Adherence and perceived barriers to oral antiviral therapy for chronic hepatitis B. Glob. Health Action 11, 1433987 (2018).

11. Tamaki, N. et al. Comparison of medication adherence and satisfaction between entecavir and tenofovir alafenamide therapy in chronic hepatitis B. J. Med. Virol. 92, 1355-1358 (2020).

12. Fisher, J. D., Fisher, W. A., Amico, K. R. \& Harman, J. J. An information-motivation-behavioral skills model of adherence to antiretroviral therapy. Health Psychol. Off. J. Div. Health Psychol. Am. Psychol. Assoc. 25, 462-473 (2006).

13. Fisher, J. D., Amico, K. R., Fisher, W. A. \& Harman, J. J. The information-motivation-behavioral skills model of antiretroviral adherence and its applications. Curr. HIV/AIDS Rep. 5, 193-203 (2008).

14. Amico, K. R. et al. The information-motivation-behavioral skills model of ART adherence in a Deep South HIV+ clinic sample. AIDS Behav. 13, 66-75 (2009).

15. World City Populations 2021. https://worldpopulationreview.com/world-cities.

16. Fisher, W. A., Fisher, J. D. \& Harman, J. The Information-Motivation-Behavioral Skills Model: A General Social Psychological Approach to Understanding and Promoting Health Behavior. in Social Psychological Foundations of Health and Illness (eds. Suls, J. \& Wallston, K. A.) 82-106 (Blackwell Publishing Ltd, 2003). doi:10.1002/9780470753552.ch4.

17. Gilead Sciences, Inc. HIGHLIGHTS OF PRESCRIBING INFORMATION: Viread (tenofovir disoproxil fumarate).

18. Nayagam, S. et al. Requirements for global elimination of hepatitis B: a modelling study. Lancet Infect. Dis. 16, 1399-1408 (2016).

19. Osterberg, L. \& Blaschke, T. Adherence to Medication. N. Engl. J. Med. 353, 487-497 (2005).

20. Martin, L. R., Williams, S. L., Haskard, K. B. \& Dimatteo, M. R. The challenge of patient adherence. Ther. Clin. Risk Manag. 1, 189-199 (2005).

21. Gilson, L. Editorial: building trust and value in health systems in low- and middle-income countries. Soc. Sci. Med. 61, 13811384 (2005).

22. Grant, M. et al. Trust of community health workers influences the acceptance of community-based maternal and child health services. Afr. J. Prim. Health Care Fam. Med. 9, 1281 (2017).

23. Gourlay, A. et al. "It Is Like That, We Didn't Understand Each Other": Exploring the Influence of Patient-Provider Interactions on Prevention of Mother-To-Child Transmission of HIV Service Use in Rural Tanzania. PLOS ONE 9, e106325 (2014).

24. Chan, O. K., Lao, T. T., Suen, S. S. H., Lau, T. K. \& Leung, T. Y. Knowledge on hepatitis B infection among pregnant women in a high endemicity area. Patient Educ. Couns. 85, 516-520 (2011). 
25. Dulin, A. J. et al. Resilience and HIV: a review of the definition and study of resilience. AIDS Care 30, S6-S17 (2018).

26. Oliveira, R. da S., Primeira, M. R., Santos, W. M. D., Paula, C. C. de \& Padoin, S. M. de M. Association between social support and adherence to anti-retroviral treatment in people living with HIV. Rev. Gaucha Enferm. 41, e20190290 (2020).

27. George, S. \& McGrath, N. Social support, disclosure and stigma and the association with non-adherence in the six months after antiretroviral therapy initiation among a cohort of HIV-positive adults in rural KwaZulu-Natal, South Africa. AIDS Care 31, 875884 (2019).

28. Campbell, L. et al. Social and Structural Determinants of Household Support for ART Adherence in Low- and Middle-Income Countries: ASystematic Review. Int. J. Environ. Res. Public. Health 17, E3808 (2020).

29. Lyon, M. E. et al. A family group approach to increasing adherence to therapy in HIV-infected youths: results of a pilot project. AIDS Patient Care STDs 17, 299-308 (2003).

30. Lumbreras, B. \& López-Pintor, E. Impact of changes in pill appearance in the adherence to angiotensin receptor blockers and in the blood pressure levels: a retrospective cohort study. BMJ Open 7, e012586 (2017).

31. Research, C. for D. E. and. From our perspective: The importance of the physical characteristics of generic drugs. FDA (2019).

32. Mokaya, J. et al. A blind spot? Confronting the stigma of hepatitis B virus (HBV) infection - A systematic review. Wellcome Open Res. 3, 29 (2018).

33. Chambers, L. A. et al. Stigma, HIV and health: a qualitative synthesis. BMC Public Health 15, 848 (2015).

34. Courtwright, A. \& Turner, A. N. Tuberculosis and Stigmatization: Pathways and Interventions. Public Health Rep. 125, 34-42 (2010).

35. Kipp, A. M. et al. Study of tuberculosis and AIDS stigma as barriers to tuberculosis treatment adherence using validated stigma scales. Int. J. Tuberc. Lung Dis. Off. J. Int. Union Tuberc. Lung Dis. 15, 1540-1545, i (2011).

36. Eni, A. O. et al. Knowledge and Awareness of Hepatitis B Virus Infection in Nigeria. Ann. Glob. Health 85, 56 (2019).

37. Mugisha, J. et al. A Study of Knowledge, Experience, and Beliefs About Hepatitis B Virus (HBV) Infection in South Western Uganda. Front. Public Health 7, 304 (2019).

38. Shah, S. A. et al. Hepatitis B awareness and knowledge in hepatitis B surface antigen-positive parturient immigrant women from West Africa in the Bronx, New York. J. Immigr. Minor. Health 17, 302-305 (2015).

39. Nankya-Mutyoba, J. et al. Correlates of hepatitis B awareness and disease-specific knowledge among pregnant women in Northern and Central Uganda: a cross-sectional study. Hepatol. Med. Policy 3, 14 (2018).

40. Sabaté, E. Adherence to long-term therapies: policy for action: meeting report, 4-5 June 2001. https://apps.who.int/iris/handle/10665/66984 (2001).

41. Heestermans, T., Browne, J. L., Aitken, S. C., Vervoort, S. C. \& Klipstein-Grobusch, K. Determinants of adherence to antiretroviral therapy among HIV-positive adults in sub-Saharan Africa: a systematic review. BMJ Glob. Health 1, e000125 (2016).

42. Faust, L. \& Yaya, S. The effect of HIV educational interventions on HIV-related knowledge, condom use, and HIV incidence in sub-Saharan Africa: a systematic review and meta-analysis. BMC Public Health 18, 1254 (2018).

43. Nozaki, I. et al. False Beliefs About ART Effectiveness, Side Effects and the Consequences of Non-retention and Non-adherence Among ART Patients in Livingstone, Zambia. AIDS Behav. 17, 122-126 (2013).

44. Young, S., Wheeler, A., McCoy, S. \& Weiser, S. D. A review of the role of food insecurity in adherence to care and treatment among adult and pediatric populations living with HIV and AIDS. AIDS Behav. 18, 505-515 (2014).

\section{Figures}




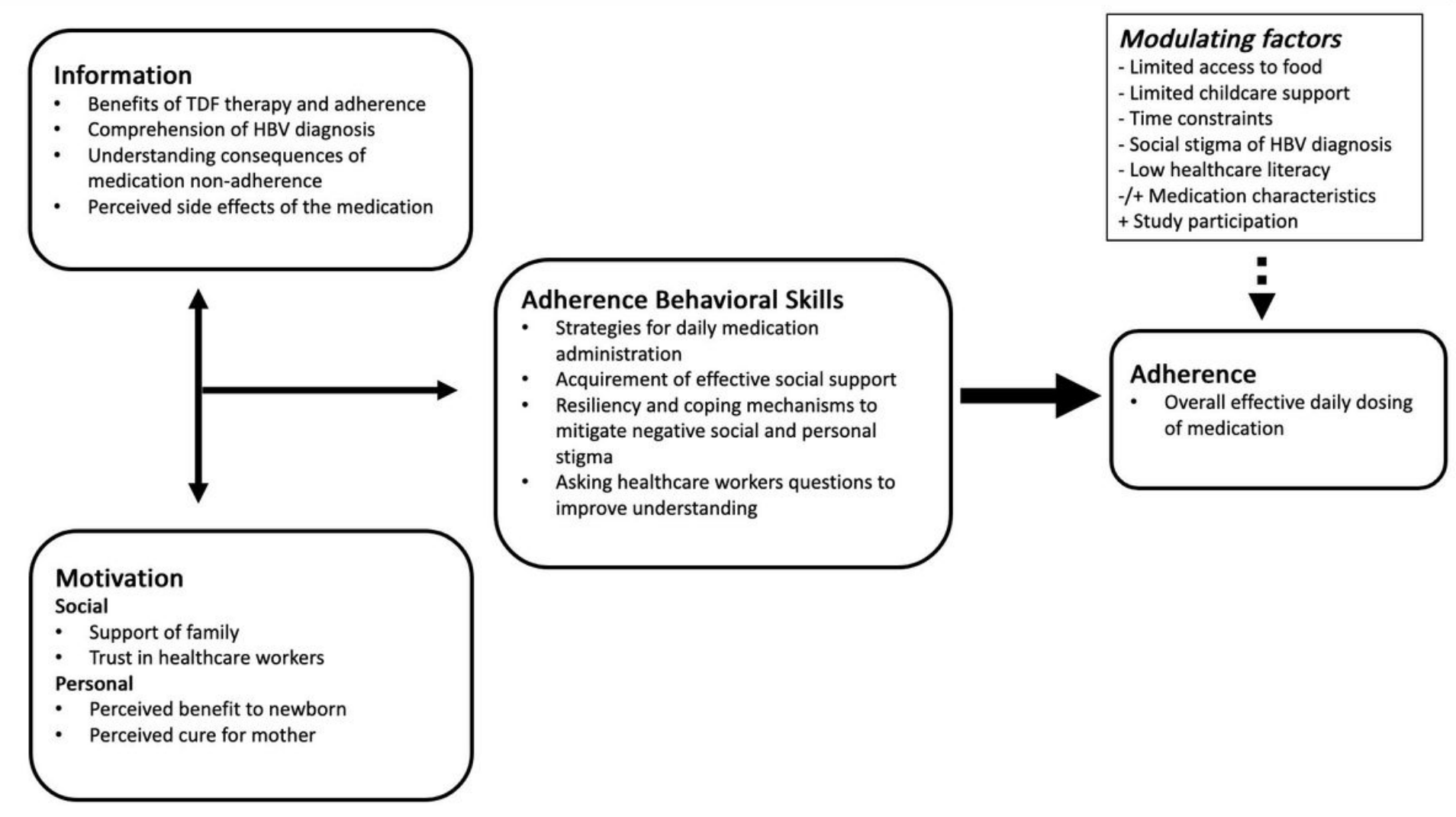

Figure 1

A modified Information-Motivation-Behavioral Skills (IMB+) model for analysis of Tenofovir adherence among pregnant women in the DRC. The positive or negative influences of these factors are indicated by plus and minus signs, respectively.

\section{Supplementary Files}

This is a list of supplementary files associated with this preprint. Click to download.

- TDFAdherenceSupplemental1.docx 